\title{
Surface morphology properties of biochars produced from different feedstocks
}

\author{
Hao Liang ${ }^{1, a}$, Lei Chen ${ }^{1, b}$ Guocheng Liu ${ }^{1, c}$, and Hao Zheng ${ }^{1, d, *}$ \\ ${ }^{1}$ College of Environmental Science and Engineering, Ocean University of China, Qingdao 266100, \\ China \\ ahaotian_47@163.com, ${ }^{b}$ ludongdaxuechenlei@163.com, ${ }^{c}$ iceliugc@126.com, \\ dzhenghao2013@ouc.edu.cn
}

*Corresponding author: zhenghao2013@ouc.edu.cn; 0532-66781068

\begin{abstract}
Keywords: biochar, broiler litter, sawdust, furfural residue, surface morphology
Abstract. The influence of feedstock and pyrolysis temperature on biochar properties has been extensively studied. This study used scanning electron microscopy (SEM) and electron dispersive $\mathrm{X}$-ray analysis (EDX) to observe surface morphology properties of the biochars produced from broiler litter (BL), saw dust (SD), furfural residue (FR) at 300-700 ${ }^{\circ} \mathrm{C}$. The SEM images showed that the biochars from SD and FR clearly retained fibrous structures of the feedstocks and were rich in macro-pores. Similarly, the FR-derived biochars produced at 500 and $700{ }^{\circ} \mathrm{C}$ contained larger quantity of pores compared to that of the FR300. The particles with irregular shape on the surface of these biochars reduced with increasing temperature, suggesting that their surface morphology changed greatly during charring at higher temperature. Mineral elements (e.g. $\mathrm{K}, \mathrm{Mg}$, and $\mathrm{P}$ ) were found in the FR-derived biochars. The abundant pores and minerals in the biochars are helpful for ameliorating soil through the supplies of micro spaces and mineral nutrition .
\end{abstract}

\section{Introduction}

In recent years, biochar, as a green material, has gained great interest in promoting carbon sequestration [1], reducing greenhouse gas emission [2], improving soil quality and increasing crop production [3], and controlling soil and water pollution [4]. Because of the difference of feedstocks, pyrolysis technologies and conditions, biochars have wide diversity of properties. Various feedstocks including forestry products, agricultural residues, animal wastes or municipal wastes can be used for producing biochar [5]. In most cases, the properties of biochars (e.g. surface area, pore volume, mineral distribution) are mainly depended on the feedstock and pyrolysis conditions [6]. For agronomic benefits from biochar, it is important to understand how the surface morphology properties are influenced by feedstock types and the pyrolysis conditions, especially the pyrolysis temperature. Scanning electron microscopy (SEM) and electron dispersive X-ray analysis (EDX) techniques provide us a direct way to observe the urface structure and mineral distribution of biochar.

Based on the biochars produced from broiler litter, sawdust and furfural residue, the objective of the present study was to investigate the surface structure and mineral distribution of biochars produced at different temperatures.

\section{Materials and methods}

Biochar preparation. Broiler litter (BL), saw dust (SD) and furfural residue (FR) were collected from a local agricultural field, furniture and chemical factory in Qingdao, china, respectively. These raw feedstocks were ground to $<0.5 \mathrm{~mm}$ and dried in an air-forced oven at $60{ }^{\circ} \mathrm{C}$ for 3 days. Each feedstock was placed in a vacuum tube furnace (O-KTF1200, Chunlei Co., China) and pyrolyzed at $700{ }^{\circ} \mathrm{C}$ for $2 \mathrm{~h}$ under a $\mathrm{N}_{2}$ flow of $500 \mathrm{~mL} \mathrm{~min}^{-1}$, respectively. Other two temperatures, 300 and $500{ }^{\circ} \mathrm{C}$, were adapted to carbonize FR into the resulting biochar samples. The BL, SD, and FR biochars were stored in an airtight container, and were referred to as BLX, SDX, FRX, where X is the pyrolysis temperature. 
SEM and EDX techniques. The surface observation of biochars was analyzed using scanning electron microscopy (SEM) (S-4800, Hitachi, Japan) and electron dispersive X-ray analysis (EDX) (7593-H, Horiba, Japan). For the observation of the above samples, we used the same SEM magnifications $(1 \mathrm{~K}, 1.5 \mathrm{~K}, 2 \mathrm{~K}, 5 \mathrm{~K}, \mathrm{~K}$ means a thousand), same acceleration voltage $(10 \mathrm{KeV})$, current $(10 \mu \mathrm{A})$, and focal length $(9-10 \mathrm{~mm})$. One spot was selected and observed for each sample to show microstructure variation. As a control, dried feedstocks were also imaged by SEM.

\section{Results and discussion}

Morphological analysis. SEM images of all feedstocks and the biochars produced at $700{ }^{\circ} \mathrm{C}$ were shown in Fig.1. BL exhibited a complex morphology due to the heterogeneous components consisting of charred remnants of seeds, hair, proteins, digested food, bedding materials [7], and minerals such as S, K and P. Compared with BL, BL700 showed that the morphology become more complex because of aggregations of mineral compounds. Furthermore, due to the dehydration and volatilization of raw materials, a small amount of pores with different sizes appeared in BL700. SD displayed longitudinal fibrous structures probably arising from the cellulosic structure of sawdust that can be grouped into fibrous, prismatic and spherical [8]. The morphology of SD700 had changed, as revealed by the irregular surface. It also showed that the plant cellular morphologies were maintained in SD700. More pores appeared in SD700, consisting with the observed pores, generally large macro-pores, in the carbonaceous surfaces and walls [9]. Similarly, FR700 retained the fibrous structures of starw plants mainly composed of individual particles of lignin with polygonal shape. FR has irregular surface itself with lots of polygonal shards attached on the surface, and the same surface morphology was observed in FR700.
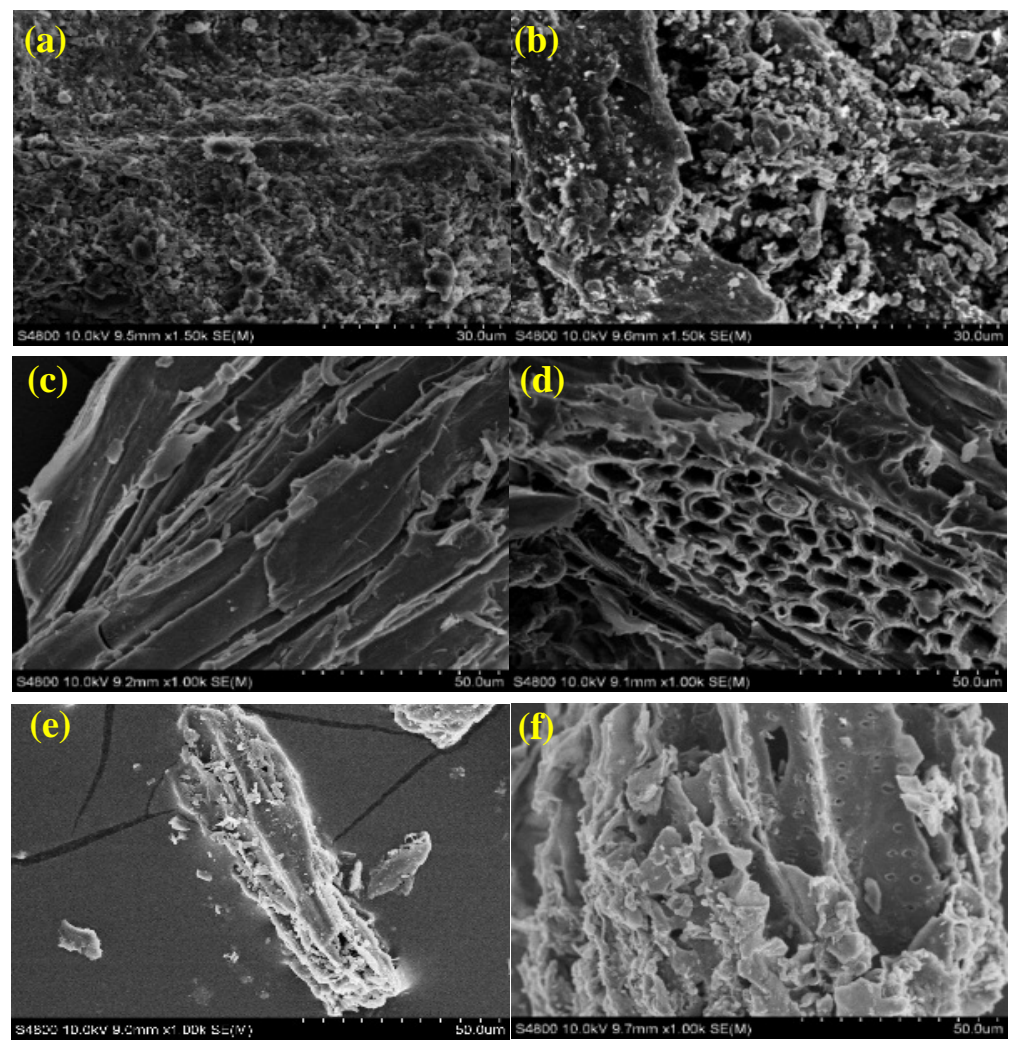

Fig. 1. Scanning electron micrograph (SEM) images of broiler litter (BL) at $60^{\circ} \mathrm{C}$ (a) and $700^{\circ} \mathrm{C}(\mathrm{b})$; saw dust (SD) at $60^{\circ} \mathrm{C} \mathrm{(c)} \mathrm{and} 700^{\circ} \mathrm{C} \mathrm{(d);} \mathrm{furfural} \mathrm{residue} \mathrm{(FR)} \mathrm{at} 60^{\circ} \mathrm{C}(\mathrm{e})$ and $700^{\circ} \mathrm{C}(\mathrm{f})$.

The SEM images of FR300, FR500 and FR700 are shown in Fig. 2a-c. The images in figure.2 show the surface morphology change influenced by temperature, and a comparison of images of (a), (b), (c) indicated that the surface of biochars trended to smooth, and something like irregular shape particles 
on the surface in FR300 had reduced. Higher pore quantity was produced with temperature increased in FR500 and FR700, which could lead to the conclusion that morphological changes in the biochars occurred to some extent during the char formation reactions. This appearance changes were supported by some research that pyrolysis temperature had a notable impact on the pore structure and morphology of biomass char. Between 200 and $500{ }^{\circ} \mathrm{C}$, the removal of a significant amount of volatile matter produced pore opening [10]. Further, the thermal decomposition of chemical bonds and the melting of some compounds can break the chemical bonds and the structure of the original material to create more pores [11].
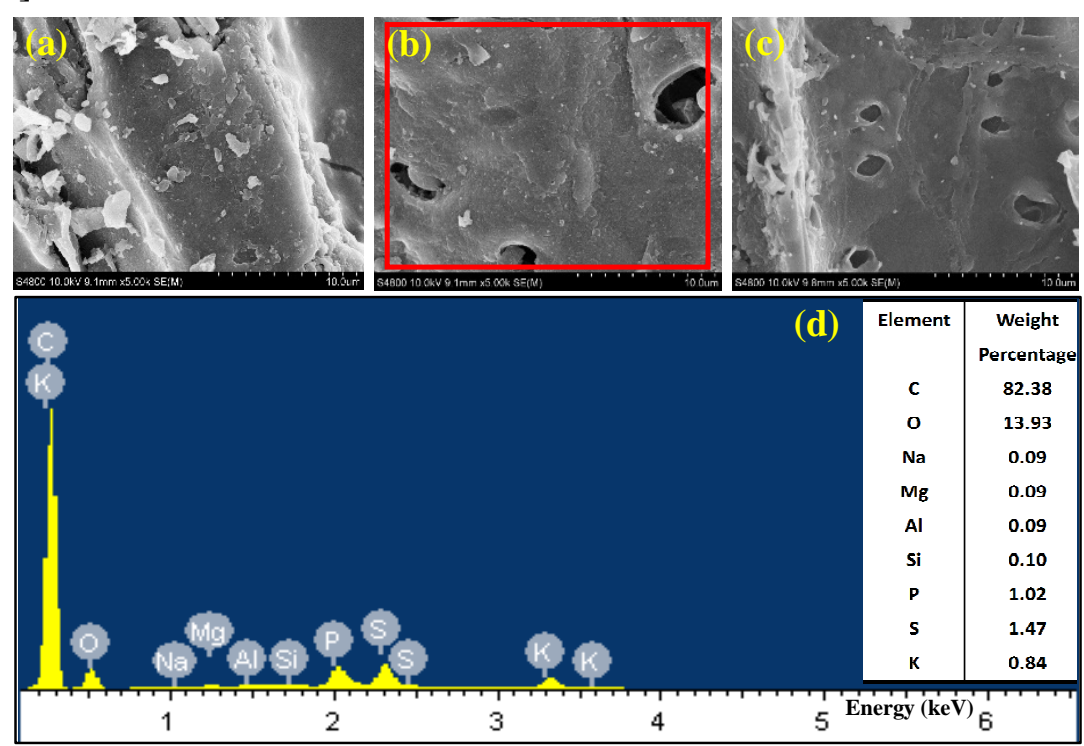

Fig. 2. Scanning electron micrographs (SEM) of biochars from furfural residue (FR) at $300{ }^{\circ} \mathrm{C} \mathrm{(a),} 500{ }^{\circ} \mathrm{C}$ (b) and $700{ }^{\circ} \mathrm{C}$ (c); (d) is electron dispersive X-ray (EDX) image of FR500 (part of highlight with red rectangle was scaned).

EDX of FR500 (Fig 2 d) indicated that $\mathrm{C}(82.4 \%)$ and $\mathrm{O}(13.9 \%)$ were the major elements of the biochar, and the mineral fractions, such as $\mathrm{Mg}(0.09 \%), \mathrm{Na}(0.09 \%), \mathrm{Al}(0.09 \%), \mathrm{Si}(0.10 \%), \mathrm{K}$ $(0.84 \%), \mathrm{P}(1.02 \%), \mathrm{S}(1.47 \%)$ could be detected. These results demonstrated that $\mathrm{C}$ was the main skeleton with $\mathrm{O}$ in the biochar samples, which may come from oxygen-containing functional groups (e.g., - $\mathrm{COOH}$ and $-\mathrm{OH}$ ) or oxygen-containing metal minerals particles (e.g. carbonate, phosphate, sulphate).

\section{Conclusions.}

Surface morphology properties of the biochars were remarkably influenced by the feedstock types and the pyrolysis temperature. The fibrous structures of sawdust and furfural residue were retained their biochars, and formed the carbon skeleton in the biochars. With increasing pyrolysis temperature, the surface morphology of the biochars was intricately changed and the pores were gradually opened. Moreover, various mineral elements on the surface of FR500 were onserved. These results could be helpful to produce designer biochar used as ameliorants for improving degraded soils.

\section{Acknowledgements}

This study was supported by National Natural Science Foundation of China (41406085, 41325013, 41573089), and Natural Science Foundation of Shandong Province (ZR2014DQ011).

\section{References}

[1] Woolf, D., et al., Sustainable biochar to mitigate global climate change. Nature Communications, 2010. 1: p. 56. 
[2] Wang, Z., et al., Characterization and influence of biochars on nitrous oxide emission from agricultural soil. Environmental Pollution, 2013. 174: p. 289-96.

[3] Zheng, H., et al., Impacts of adding biochar on nitrogen retention and bioavailability in agricultural soil. Geoderma, 2013. 206: p. 32-39.

[4] Khan, S., et al., Sewage sludge biochar influence upon rice (Oryza sativa L) yield, metal bioaccumulation and greenhouse gas emissions from acidic paddy soil. Environmental Science and Technolgy, 2013. 47(15): p. 8624-32.

[5] Tan, X., et al., Application of biochar for the removal of pollutants from aqueous solutions. Chemosphere, 2015.125: p. 70-85

[6] Lehmann, J., et al., Biochar for Environmental Management: Science and Implemetation. second ed. 2015, London Earthscan. 997.

[7] Suliman, W., et al., Influence of feedstock source and pyrolysis temperature on biochar bulk and surface properties. Biomass and Bioenergy, 2016. 84: p. 37-48.

[8] Joseph, S. D., et al., An investigation into the reactions of biochar in soil. Australian Journal of Soil Research, 2010. 48: p. 501-515.

[9] Pituello, C., et al., Characterization of chemical-physical, structural and morphological properties of biochars from biowastes produced at different temperatures. Journal of Soils and Sediments, 2014. 15(4): p. 792-804.

[10] Sheau, H., et al., Carbonization process of Moso bamboo (Phyllostachys pubescens) charcoal and its governing thermodynamics. Journal of Analytical and Applied Pyrolysis, 2014. 107: p. 9-16.

[11] Fu, P., et al., Effects of Pyrolysis Temperature on Characteristics of Porosity in Biomass Chars. In 2009 International Conference on Energy and Environment Technology, 2009: p. 109-112.

[12] Chen, T., et al., Effect of Selective Condensation on the Characterization of Bio-oil from Pine Sawdust Fast Pyrolysis Using a Fluidized-Bed Reactor. Energy \& Fuels, 2010. 24(12): p. 6616-6623. 